\title{
The Intention to Donate Blood: An Analysis of Socio-Demographic Determinants
}

\author{
Nur Zainie Abd Hamid, Rohaida Basiruddin, and Narehan Hassan
}

\begin{abstract}
The current trends of blood supply shortage have raised the concern about the ability to meet the blood product demand in the future. At the time of high demand for blood products especially during festive seasons, Malaysia is unable to encounter the demand. As a result, the quality of human life is affected. This has created the prerequisite to understand the scenario and recognizing the factors that may influence people's intention to donate blood. The purpose of this survey-based study is to investigate the implication of socio-demographic factors in measuring the intention of the public to involve in a blood donation program specifically in Perlis population, Malaysia. The findings indicated that, among the socio-demographic factors, gender is predicted to have the greatest association with intention to donate blood than others. Besides, individuals who have blood donation experience in life were more desired to do again their behavior in the future than those who are not. The new discoveries generated are believed to be valuable for future research as well as in designing future blood donation program in order to encourage the participation of the public.
\end{abstract}

Index Terms-Blood donation, intention to donate blood, socio-demographic determinants.

\section{INTRODUCTION}

World nowadays is constantly facing a blood shortage, whereby only less than $45 \%$ blood are being collected through alternative programs in most of the developing countries that composed of $82 \%$ of global population [1]. Situation in the United State, the blood supply is basically depends on donations from volunteer donors who usually the public. A survey done by HHS in year 2006 among 1,735 blood centers and hospitals in United State showed that, blood collection per thousand US population has decreased by 2.7 percent between the years 2001 to 2004 [2]. Even nowadays, they had reached the target of $30 \%$ of their residents to involve in blood donation, the increasing demand for blood products has caused them to work out more for blood donation in order to cope with insufficient blood supply in the country.

In fact, Malaysia forced to raise the red flag for more donations and to announce the level of national blood is critical due to the unlimited usage of the blood in medication.

Manuscript received May 28, 2013; revised July 3, 2013. The Intention to Donate Blood: An Analysis of Socio-Demographic Determinants.

Nur Zainie Abd Hamid and Narehan Hassan are with the Business Management, Universiti Teknologi MARA, 42300 Puncak Alam, Selangor, Malaysia (e-mail: nurzainie60@puncakalam.uitm.edu.my, drnarehan@puncakalam.uitm.edu.my).

Rohaida Basiruddin is with the International Business School, Universiti Teknologi Malaysia, 54100 Kuala Lumpur, Malaysia (e-mail: rohaida@ic.utm.my).
One of the greatest reasons for the shortage is due to the low turnout of donor during the festive seasons [3]. This has brings problem especially for those who suffer from serious illness need to receive blood regularly to support their daily life especially those with thalassemia [4] where most of the events are unexpected and accidently happen. It is perceived as a serious scenario to be handled, otherwise, the whole world population will be affected since it involves life-threatening concern. This is because, it is undoubtful that, the blood donation has contributed to the different of death and life of a person.

Furthermore, an increasing demand for blood in almost all medical centers throughout Malaysia also indicated that, there is also the requirement for more blood donors. In year 2010, the Malaysian National Blood Centre has targeted that, more than $10 \%$ of Malaysian will involve in blood donation, but, unfortunately, only $3 \%$ were reported to do so. Although the blood donation programs are organized everywhere, throughout the country, but still, minimal participation is recorded. This has created a need to understand the donors in an effort to recruit as well as retain the current donors who are willing to donate. Therefore, an effort to render more volunteer donors to get a large pool of blood donors is critical in maintaining the blood supply over time [5]. It is vital for every member of society to cooperate and ensure that every blood bank not only has sufficient but also safe blood supply. However, not all are willing to do so. Even there were number of studies conducted in Malaysia to predict the intention to donate blood among people in different group, however, it is still insufficient [6]. It is important to investigate the factors that affecting the blood donation behavior in order to develop an effective blood donation campaign or program [7]. Thus, this study is critical in an attempt to access the important socio-demographic factors that may influence an individual intention to donate blood and to what extend the factors are significant in predicting the intention.

\section{LiterATURE REVIEW}

Blood donation occurs when a volunteer individual drawn their blood for specific medical purposes. It involves a simple process within 7 to 10 minutes whereby only $450 \mathrm{ml}$ of blood will be taken from each donor to save about three lives. Some basic criteria that need to be fulfilled by an individual before he or she can donate their blood are healthy on the day of donation, body weight exceeding 45 kilograms, free from any health problem, not pregnant, not having menstruation, not breast feeding and have enough sleep a day before. Even though only those who are above 18 years old are encouraged 
to do so, however, those below also may involve except they need to get a permission from their guidance or parent. This communicates that everybody qualified can donate their blood regardless of their type of occupation, level of income, level of education and so on.

Overview about the behavior of blood donation is being discussed comprehensively in a number of prior studies [8], [9]. The studies have provided a ground and direction for current researchers to explore the blood donation field. With respect to current research that attempted to access the effect of individual's socio-demographic factors with their intention to perform blood donation behaviour, Godin, Sheeran, Conner, Germain, Blondeau, Gagne, Beaulieu and Naccache has emphasized the important of identifying the socio-demographic of the respondents in an attempt to conduct and compare group in a study since it will be easy to make a prediction and study the difference existed between different socio-demographic characteristics [10]. In fact, it has been studied that, socio-demographic factors may be able to develop a certain amount of conscious effort in individual in which will carry a behavioral intentions [11]. This has brings the meaning that, it may not only shape the intention, but also the attitude and behavior that is consistent with the intention [12]. Generally, there are many socio-demographic factors such as gender, age, education level, income level, marital status, occupation, religion and average size of family [13] however, the most common factor been studied so far is the effect of gender differences.

Many studies have proven that, socio-demographic factors are significant in predicting one's intention or behavior. One of them is work out by Oswalt where he found that almost $90 \%$ of the blood donor population was male [8]. He also revealed the same findings with others nine studies which indicated that, almost $70 \%$ of the blood donor population was male. Also of the same interest, Ben Natan and Gorkov lately has supported the evidence by concluding in their study among blood donors that, more than $70 \%$ of their Israelis respondents were male in which strengthen the finding of prior research [14].

Furthermore, there was also study conducted to reveal the association between individual ages with their intention and actual behavior of blood donation. Piliavin and Callero indicated that, the average age of blood donors were between 33 to 38 years old [9]. However, that was in 1970s to 1980s. Later, it was found that, the average age was decreased and the willingness to donate blood will decline with the respondents' age [15]. Even, a more recent study conducted by Saluja's and Ahuja in tertiary care hospitals has indicated the same direction whereby they concluded that younger people had a high willingness to donate blood compared to the elders [16]. It was seen in the study that, more than half of the donors were in the age group of 18 to 30 years old and only a single percentage of the donors are aged above 50 years old.

Another socio-demographic factor is the education level. In a study conducted by Tscheulin and Lindenmeier, they found that the willingness to donate blood does increase with the level of education [15]. A consistent result also was found in a study conducted in the year 2006 that taken from Ahuja and Saluja whereby they found that $76 \%$ of the study respondents were among those who has a college education, has bachelor degree and has a master's degree or higher [16]. In fact, a number of other studies also indicated the same findings whereby they found that, respondents with high education level such as students and soldiers where tend to have the intention to donate blood.

Since majority of the literatures reviewed suggested that there were significant influences of socio-demographic factors on the individual intention and actual behavior of blood donation [11]-[13], therefore, the following hypotheses were prepared in an attempt to access the socio-demographic factors influence on the intention to donate blood:

H1: There is a statistically significant association between the socio-demographic factors with the intention to donate blood.

$\mathrm{H} 2$ : Men have higher intention to donate blood than women.

H3: The willingness to donate blood increase with education level.

H4: The younger have more intention to donate blood than the elders.

Also of interest, prior studies reported that, ever donor will have higher intention to donate blood than those who never donated blood in life [10]. This was also confirmed by a pilot study conducted by Mehrdad, Latiffah, Syed Tajuddin, Parichehr and Mohamed in a few years later whereby, they also found that, the majority of the students who ever donated their blood had a high willingness to donate blood than potential donor [6]. In fact, Kam, et al. also demonstrated the same direction whereby they managed to establish that, students who have more knowledge about the blood donation experienced more blood donation than who are not [7]. With regards to this study, since the researcher recognized that, individual knowledge about the blood donation may influence an individual behavior towards blood donation, the following hypothesis 5 was prepared:

H5: Repeat donors have more intention to donate blood than who never donated their blood in life.

\section{Methodology}

\section{A. Population}

This study was conducted between 1 March 2012 and 31 June 2012. The sample comprised of a 384 respondents (192 males and 192 females) who were conveniently selected from six areas in Perlis, Malaysia. They are all Malay residents. The population characteristics were homogenous since all of them came from rural areas. The respondents were approached personally by the researcher in the residential areas throughout the two weeks. A maximum of 30 minutes was given for each respondent to complete the questionnaire. Disable respondents such as those with vision problems and reading problems were assisted by the researcher. The study was limited to those aged between 18 to 50 years old and without any health complication that might bother the eligibility to donate blood.

\section{B. Instrument}

A set of questionnaires was adapted by the researcher from 
prior studies accompanied with a cover letter outlining the purpose of the study. All questions were adapted from BenNatan and Gorkov, Mehrdad, Latiffah, Syed Tajuddin, Parichehr and Mohamed and Robinson, Natalie, Barbara, Katherine, Melissa and Terry [6]-[17]. The researcher decided to prepare a questionnaire in bi-language since the population units were mostly come from rural areas. It contained 7 items arranged in two sections. The first section comprised of 4 items that were used to collect respondents' demographic information, blood donation experience and the amount of blood donation in the past and the remaining 3 items in second section were related to the individual's intention. The individual's intention was ranked based on 4-Likert scale from 1 (Strongly Disagree) to 4 (Strongly Agree). These three items used "I expect to...", "I want to..." and "I intend to.." that are believed can demonstrate internal consistency for the public intention.

\section{Data Analysis}

All data were entered manually into spss 17.0 database software. Descriptive and frequency statistics were used to examine the socio-demographic information of all respondents. Spearman's Correlation Coefficient Test were performed to examine the association strength between socio-demographic factors with the intention to donate blood A significant (p) value of less than 0.01 is considered as statistically significant. Mann-Wallis Test and Kruskal-Wallis Test were used in order to compare between the two groups.

\section{FINDINGS AND DisCUSSION}

\section{A. Background of the Respondents}

Generally, the study involved both donor and non-donor group. Donor group is referred to individuals who ever donated their blood in live while, non-donor group is referred to individuals who never donated their blood in live. The questionnaires were distributed equally between male and female, regardless of their age. $46.6 \%$ from the respondents are aged between 31 to 40 years-old, $27.6 \%$ are aged between 18 to 30 years-old while the remaining are aged between 41 to 50 years-old.

In term of education level, surprisingly, $41.4 \%$ from the respondents have at least a diploma. This finding has contributed to the false believed that, it is not true people who come from rural areas were uneducated. Another $30.5 \%$ hold a minimum education background while the remaining $28.1 \%$ have a high qualification of master degree and $\mathrm{PhD}$.

When comes to the distribution of blood donation experience, it can be seen that, most of the respondents which is nearly $70 \%$ or equal to 263 from them have never involved in blood donation. Therefore, it is to be said that, the population is relevant to be studied since most of them are not yet be a donor. Among non-donor group, 156 from them are female. This finding indicated a gap between gender towards the actual behavior of blood donation, where, the actual behavior of blood donation among female are lower than male. In other words, male are the contributor group in blood donation. This is supported by the next finding where, it is found that, over 121 donors, 85 of them are male, which is equal to $70 \%$. Not to forget, majority of the donors are also known as repeat donors.

\section{B. The Influence of Socio-Demographic Factors on the Intention to Donate Blood}

The result of the study about the influence of socio-demographic factors on the intention to donate blood is presented in Tables I until V. It is basically based on the results drawn from Spearman's Rank Order Correlation Coefficient, Mann-Whitney U-test and Kruskal Wallis test.

TABLE I: CORRELATION BETWEEN SOCIO-DEMOGRAPHIC FACTORS WITH THE INTENTION TO DONATE BLOOD

\begin{tabular}{llrrr}
\hline \hline \multirow{2}{*}{ Intention } & & Gender & Age & Education Level \\
\hline & $\begin{array}{l}\text { Correlation } \\
\text { Coefficient }\end{array}$ & $-.292^{* *}$ & -.029 & .066 \\
\cline { 2 - 5 } & Sig. (2-tailed) & .000 & .568 & .198 \\
\cline { 2 - 5 } & $\mathrm{N}$ & 384 & 384 & 384 \\
\hline \hline
\end{tabular}

* Correlation significant at the level 0.01 (1-tailed)

As implied in the following Table I, there is an association between socio-demographic factors with the intention to donate blood [10]. The highest significant association was found in gender whereby, the findings indicated that, gender influence better than other socio-demographic factors for the intention to donate blood among the tested population in which the finding is found to be consistent with Oswalt, Boulware, Ratner, Cooper, Sosa, LaVeist and Powe and Ben Natan and Gorkov [8]-[18]. Other variables, age and education level indicated non-significant value with a very low association. Since gender is the only variable with significant value, therefore, $\mathrm{H} 1$ to be rejected.

TABLE II: MANN-WHITNEY U-TEST FOR THE INTENTION TO DONATE BLOOD OF DIFFERENT GENDER

\begin{tabular}{llccr}
\hline \hline & Gender & $\mathrm{N}$ & Mean Rank & Sum of Ranks \\
\hline Intention & Male & 192 & 223.07 & 42829.50 \\
\cline { 2 - 5 } & Female & 192 & 161.93 & 31090.50 \\
\cline { 2 - 5 } & Total & 384 & & \\
\hline \hline
\end{tabular}

Meanwhile, in order to determine the preferable gender to engage in blood donation, only 121 non-donors and 121 donors are selected in order to remove the bias. The result is generated through Mann-Whitney U-Test performed as shown in the Table II. It was found that, the male group in Perlis population will more likely to engage in blood donation than female group. They have more willingness or high intention to donate blood that female. This, in general may be due to the characteristic that a male has for instance more courageous and responsible than a female. The finding supports current findings found by Ben Natan and Gorkov and previously by Oswalt, whereby, the prior studies explained the foundation of the evidence on the influence of gender with the intention to donate blood [8]-[11]. As well, previous finding in the descriptive statistic can also be supported since it has been proven that, the low intention to donate blood among the female group has caused them to be the least blood contributor. Thus, $\mathrm{H} 2$ to be supported. 
With respect to the education level as shown in Table III, the same approach used in Table II was used whereby only atotal number of 60 respondents were selected to represent one education level group. Respondent with $\mathrm{PhD}$ degree has been excluded from this statistical test since there is only one respondent with this characteristic. The finding showed that, the willingness to donate blood did not increase with education level but contradict. This indicated the intention to donate blood among the population is not influenced by the level of education and it is not appropriate to recognize the blood donor group through the factor. In other words, those with higher education level are not necessarily will involve in the blood donation. Thus, the finding clarification has caused $\mathrm{H} 3$ to be rejected and the research results from Tscheulin and Lindenmeier cannot be supported [15].

TABLE III: KRUSKAL-WILLIS TEST FOR THE WILLINGNESS TO DONATE BLOOD OF DIFFERENT EDUCATIONAL BACKGROUND

\begin{tabular}{lllr}
\hline \hline \multicolumn{1}{c}{ Education Level } & $\mathrm{N}$ & Mean Rank \\
\hline \hline Intention & Certificate and Below & 60 & 90.88 \\
\cline { 2 - 4 } & Diploma & 60 & 92.46 \\
\cline { 2 - 4 } & Bachelor Degree & 60 & 88.16 \\
\cline { 2 - 4 } & Total & 180 & \\
\hline \hline
\end{tabular}

Notes: $H(2)=0.237, p=0.888$

TABLE IV: KRUSKAL-WILLIS TEST FOR THE WILLINGNESS TO DONATE BLOOD OF DIFFERENT AGE

\begin{tabular}{llcr}
\hline \hline \multicolumn{2}{c}{ Age } & $\mathrm{N}$ & Mean Rank \\
\hline \hline Intention & 18 To 30 Years Old & 60 & 94.33 \\
\cline { 2 - 4 } & 31 TO 40 Years Old & 60 & 79.20 \\
\cline { 2 - 4 } & 41 TO 50 Years Old & 60 & 97.98 \\
\cline { 2 - 4 } & Total & 180 & \\
\hline \hline Notes: $H(2)=0.237, p=0.888$ & &
\end{tabular}

Contrary, however, this study did not support the finding by Pilliavin and Callero, Tscheulin and Linenmeier and Saluja's and Ahuja, whereby, the finding showed in Table IV revealed the willingness and the intention to perform the behavior of blood donation did not increase with age [9]-[16]. For this reason, the H3 was rejected. This inconsistent finding may be due to the characteristic of the population being selected in this study [11] since, this study is conducted in Malaysia and also the researcher did not make an attempt to fairly distribute the questionnaire survey based on specific demographic factors. Besides, the finding also implied that, blood donors in the population may involve individual in all ages.

TABLE V: MANN-WHITNEY U-TEST FOR THE INTENTION TO DONATE BLOOD BASED ON EXPERIENCE

\begin{tabular}{llrrr}
\hline \hline & $\begin{array}{l}\text { Blood Donation } \\
\text { Experience }\end{array}$ & $\mathrm{N}$ & \multicolumn{2}{c}{$\begin{array}{l}\text { Mean } \\
\text { Rank Sum of Ranks }\end{array}$} \\
\hline \hline \multirow{2}{*}{ Intention } & Yes & 121 & 171.52 & 20754.00 \\
\cline { 2 - 5 } & No & 121 & 71.48 & 8649.00 \\
\cline { 2 - 5 } & Total & 242 & & \\
\hline \hline
\end{tabular}

Notes: $U=1268, p=0.00$

In order to answer the last hypothesis, 121 donors and 121 non-donors were selected conveniently to perform the Mann-Whitney U-Test. It is similar to the approach used to answer the H2. All donors are selected while only selected non-donors with specific characteristics are included in this analysis. The result in Table $\mathrm{V}$ showed a consistent finding with a study being conducted in Korea where an individual who ever donated their blood was found to have greater intention to donate blood [7]. This is similar to the study performed among Israelis who demonstrated that, Israelis with the experience of blood donation have greater intention to donate blood again compared to who never done so [10]. It implied that, once an individual involve in the blood donation, there was a high possibility that the same individual will involve again in the future or in other words, to become a repeat donor. The consistency among the study has confirmed that, the intention to donate blood also will be influenced by the blood donation experience hold by an individual and therefore, H5 was supported.

\section{CONCLUSION}

Better understanding of blood donation is crucial to ensure that the blood supply is sufficient for use. It is an urgency to carry out more successful blood donation events especially in vital areas such as Perlis. Particularly, this study is attempting to provide sufficient understanding on the socio-demographics factors that may influence an individual intention to donate blood and at the same time to increase the level of blood supply in the blood banks. The findings and results basically has provided some guidelines for authority body, such as the Ministry of Health, Malaysia or specifically the Department of Health in Perlis, Malaysia to treat and design their blood donation program to be more effective in the future for the purpose of closing the gaps of blood shortage. This effort is important because without exploring the root causes, the authority will not be able to discover the barriers lying behind the blood shortage issue.

At the completion of this study, the researchers realized, the population being studied has certain characteristics that may differ them from others population in the world. The following are the characteristics of blood donors in Perlis as being derived throughout the findings of the study:

- Blood donation in Perlis population involved more man than woman.

- Gender plays significant role in predicting the intention to donate blood in the population.

- An individual who ever donated their blood previously have higher intention to donate blood again in the future compared to the individual that never donated their blood.

The ultimate goal of blood donation research is to foster the participation of individuals, generally for the whole population. With respect to this effort, it is necessary to identify the critical factors that are most likely can predict the actual behavior and intention of individuals. Therefore, a further research is recommended to study a larger population so that, the concept of generalization can be applied. Besides, the need to study from various ethnicity aspects also should be considered since Malaysia is comprised of unique composition groups such as Malay, Chinese, Indian as well as Sabah and Sarawak bumiputra. The findings of such study may then be appropriate and significant to be applied to the 
whole population of Malaysia because the more heterogeneity of the studied population, the better the results will be. Besides, the use of open ended question may also be implemented since, respondents can supply their sincere answer and give reasons for their willingness or unwillingness to involve in blood donation instead of completely relying on the answers given in the questionnaire. Last but not least, the formation of focus group also can be done to have more accurate and perfect data. By doing so, better inputs can be obtained since the respondents are approached individually.

\section{ACKNOWLEDGMENT}

The authors gratefully thank the contribution by Dean of Faculty Business Management, Universiti Teknologi MARA (UiTM), Malaysia and Dean of International Business School, Universiti Teknologi Malaysia (UTM), Malaysia. A special thank also goes to the family members and colleagues for the guidance and support which extensively contributed to the quality and completion of this study.

\section{REFERENCES}

[1] S. V. D. Boogard. (June 2011). More blood, more life: Argentina's hunt for new donors. [Online]. Available: http://www.argentinaindependent.com/currentaffairs/newsfromargenti na/more-blood-more-life-argentinas-hunt-for-new-donors/

[2] A. T. Schnaubelt, "Factors influencing a military blood donor's selection to donate: An application of the theory of planned behavior," Dissertation, Virginia Commonwealth University, Richmond, Virginia, 2010.

[3] News Straits Times. (December 2011). Blood donation appeal ahead of festivals. [Online]. Available: http://www.nst.com.my/local/general/blood-donation-appeal-ahead-of -festivals- 1.25949

[4] H. Rosline, S. A. Ahmed, F. S. A. Joudi, M. Rapiaah, N. N. Naing, and N. A. Adam, "Thalassemia among blood donor at the Hospital Universiti Sains Malaysia," Southeast Asian Journal of Medical Public Health, vol. 37, no. 3, pp. 549-562, 2006.

[5] O. Marantidou, L. Loukopoulou, E. Zervou, G. Martinis, A. Egglezou, P. Fountouli, P. Dimoxenous, M. Parara, M. Gavalaki, and A. Maniatis, "Factors that motivate and hinder blood donation in Greece," Journal of Transfusion Medicine, vol. 17, no. 6, pp. 443-450, 2007.

[6] J. Mehrdad, L. Latiffah, S. H. S. Tajuddin, H. Parichehr, and O. Mohamed, "Development of a questionnaire for assessing factors predicting blood donation among university students: A Pilot Study," Southeast Asian Journal Trop. Medical Public Health, vol. 41, no. 3, pp. 660-666, 2010.

[7] S. Kam, S. A. Kim, Y. S. Kang, K. S. Park, J. H. Son, M. H. Yeh, K. E. Lee, J. G. Kim, and D. H. Song, "Factors affecting blood donation in university students," Korean J Blood Transfusion, vol. 8, no. 2, pp. 113-124, 1997.

[8] R. M. Oswalt, "A review of blood donor motivation and recruitment," Journal of Transfusion, vol. 17, pp. 123-135, 1977.

[9] J. A. Piliavin and Callero, "Why do they give the gift of life? A review of research on blood donors since," Journal of Transfusion, vol. 30, pp. 444-459, 1991.

[10] G. Godin, P. Sheeran, M. Conner, M. Germain, D. Blondeau, C. Gagne, D. Beaulieu, and H. Naccache, "Factors explaining the intention to give blood among the general population," Journal of Sanguinis, vol. 89, pp. 140-149, 2005.

[11] M. Josses and K. Sam, "Attitudinal and socio-demographic effects on willingness to pay for water services and actual payment behavior," Urban Water Journal, vol. 7, no. 5, pp. 287-300, 2010.

[12] Q. Yao and L. Wang, "Consumer purchase intention towards genetically modified food: Beneficial, price, socio-demographic and label determinants," International Journal of Trade, Economics and Finance, vol. 3, no. 3, pp. 176-182, 2012.

[13] A. Wokje and S. Linda, "Factors related to household energy use and intention to reduce it: The role of psychological and socio-demographic variables," Human Ecology Review, vol. 18, no. 1, pp. 30-40, 2011.
[14] M. B. Natan and L. Gorkov, "Investigating the factors affecting blood donation among Israelis," International Emergency Nursing, vol. 1 no. 3, pp. 1-7, 2010.

[15] D. K. Tscheulin and J. Lindenmeier, "The willingness to donate blood: An empirical analysis of socio-demographic and motivation-related determinants," Health Services Management Research, vol. 18, pp. 165-174, 2005.

[16] G. P. Saluja's and V. Ahuja, "Assessment of blood donors' perception in a hospital blood bank and their intention for future donation," Health and Population: Perspectives and Issues, vol. 32, no. 2, pp. 78-85, 2009.

[17] N. G. Robinson, B. M. Masser, K. M. White, M. K. Hyde, and D. J. Terry, "Predicting intentions to donate blood among non-donors in Australia: An extended Theory of Planned Behavior," Journal of Transfusion, vol. 48, no. 12, pp. 2559-2567, 2008.

[18] L. E. Boulware, L. E. Ratner, L. A. Cooper, J. A. Sosa, T. A. L. Veist, and N. R. Powe, "Understanding disparities in donor behavior: Race and gender differences in willingness to donate blood and cadaveric organs," Journal of Medical Care, vol. 40, no. 2, pp. 85-95, 2002.

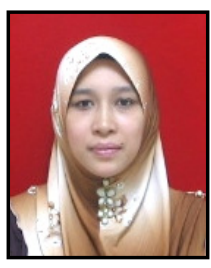

Nur Zainie Abd Hamid was born in Perlis, Malaysia on November 28, 1986. She holds a master degree in MBA healthcare management from International Business School (IBS), UTM, Kuala Lumpur in year 2012. Previously, she has worked with Dommal's Food Sdn. Bhd. (Domino's Pizza) as an administrative officer for about one years. Currently, she is working with UiTM, in Puncak Alam Campus, Selangor as a lecturer. She is interested to explore and study the area of huminity, sociality and health. Ms. Nur Zainie has been awarded with schorlarship from UiTM under the Young Lecturer Scheme as well as the Ministry of Higher Education and has received the best student awards for Bachelor Degree in Health Administration (Hons.) program and the best student for Faculty of Office Management and Technology, UiTM, Shah Alam, Malaysia in year 2009.

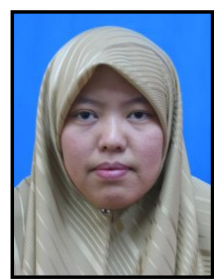

Rohaida Basiruddin was born in Sarawak, Malaysia on August 19, 1978. She holds a Ph.D in accounting and financing from Durham University, United Kingdom in year 2011. She has worked as an account supervisor at PGEO Edible Oils Sdn. Bhd. In Setiawan, Perak, Malaysia for 2 years, as an account executive and group office manager at Azlina Abdul Aziz \& Associates in Ampang, Selangor, Malaysia for two year and as an account officer at Eastbourne Corporation Bhd in Selangor. Currently, she served as a senior lecturer at IBS, UTM, Kuala Lumpur. She has published a book entitled Corporate Governance, Audit Quality and Opportunistic Earning: An Empirical Analysis of the Relation between Governance Practice, Audit Quality and Earning Management in the UK, LAP Lambert Academic Publishing, ISBN 978-3-8465-1326-2.

Dr. Rohaida has been awarded as a member of Golden Key National Honor Society, scholarship from Majlis Amanah Raya MARA for bachelor degree and scholarship from UTM and Ministry of Higher Education for master degree.

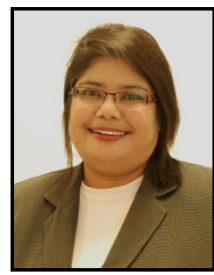

Narehan Hassan was born in Klang, Malaysia on August 13, 1964. She holds a Ph.D in education (student development) from Eastern Illinois University, United State. Since 1987, she used to be a training manager in Westport, Klang, teaching assistant in Eastern Illinois University (USA), deputy dean (Student Affairs and Alumni) in UiTM and Head Of community development at Office of the Deputy Vice Chancellor. Currently, she is serving UiTM as an associate professor at the Center for Applied Management, Faculty of Business Management, in Puncak Alam Campus, Malaysia. Until today, she has involved in number of journals and books publication. Associate Prof. Dr. Narehan Hassan has received a number of awards including the scholarship of young lecturer scheme of UiTM, UiTM's Outstanding Performance Awards and Eastern Illinois University's Global Ambassador Award. 